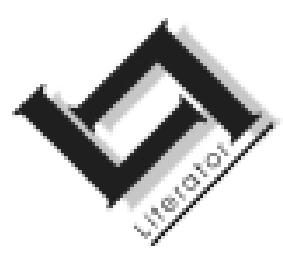

\title{
Vrouekarakters in enkele prosawerke van C.M. van den Heever
}

\author{
Elize Botha \\ Emeritus-professor: Departement Afrikaans \\ Universiteit van Suid-Afrika \\ PRETORIA
}

\section{Abstract}

The role of women in some prose works of C.M. van den Heever

Re-reading the C.M. van den Heever "classics" Somer (1935) and Laat vrugte (1939) within the framework of Van den Heever criticism through the years, one becomes aware that central themes in his oeuvre are acted out by women. The beautiful young girl Linda in Somer embodies the sadness of the transcience of beauty and happiness. Through Ouma Willa, Betta and Johanna - three women from three generations in Laat vrugte the theme of the endurance of the memory of love and passion beyond decay and death is expressed. A cursory examination of other and earlier works by Van den Heever - Op die plaas (1927), Langs die grootpad (1928), Kromburg (1937) and the short story "Leuens" (Lies) from Vuurvlieg en sterre (1934) - bears out the observation that women express core meanings in C.M. van den Heever's prose works.

\section{Opsomming}

Vrouekarakters in enkele prosawerke van C.M. van den Heever

By die herlees van die twee klassieke tekste van C.M. van den Heever, Somer (1935) en Laat vrugte (1939), binne die raamwerk van Van den Heever-kritiek deur die jare, word 'n mens daarvan bewus dat temas wat sentraal staan in die Van den Heever-oeuvre deur vrouekarakters in sy werk verwoord en verbeeld word. Die mooi jongmeisie Linda in Somer beliggaam die droefheid oor die verganklikheid van skoonheid en geluk. Deur Ouma Willa, Betta en Johanna - drie vroue uit drie generasies in Laat vrugte - word die duursaamheid van die herinnering aan liefde en hartstog, verby verval en dood, uitgebeeld. 'n Vlugtige verkenning van ander vroeë werke van C.M. van den Heever - Op die plaas (1927), Langs die grootpad (1928), Kromburg (1937) en die kortverhaal "Leuens" uit Vuurvlieg en sterre (1934) - bevestig die waarneming dat vroue kernbetekenisse in C.M. van den Heever se prosawerk uitdruk. 


\section{Her-lesers en her-lesings}

Liefhebberlesers onderskei hulle onder andere daarin dat hulle herlesers is (Nabokov, 1983:3). Vir wie "van dié getal is", en ek word self ook daarby getel, is dit geen swarigheid om terug te keer na boeke wat ons vroeër gelees en liefgehad het nie. Soms is ons teleurgestel; soms het ons met die gang van jare so as lesers verander dat ons nie meer tuis is in die geselskap van die ou bemindes nie. Maar gelukkig, so dikwels vind ons by so 'n terugkeer dat die vroeëre beminde ons nog bekoor, maar op 'n wyse wat ons nooit so beleef het in die prille jare van ons kennismaking nie. Dié groot geluk het ek deur die jare telkens ervaar as ek moes terugkeer na die twee klassieke tekste van C.M. van den Heever: Somer en Laat vrugte.

Dit is 'n waagstuk om na baie jare die effek wat 'n boek op jou kon gehad het by die eerste lees daarvan, te probeer herontdek. Tog, wat Somer betref: soos ek dit onthou, was dit die uitbeelding van die plaas- en natuurlewe wat my in daardie vroeë eerste leesjare aangegryp het. Van den Heever het woorde gehad vir 'n kind se belewenis van die geweld van natuurkragte; vir die skone gang van die seisoene oor die SuidAfrikaanse veld. En as 'n mens die bladsye sou tel, die verteltyd wat hieraan afgestaan word, sou jy wel kon sê dat landskap, aarde-enuitspansel, hoofspelers is in Somer.

Toe ek as 'n ietwat ouer hoërskoolleser Somer weer ter hand moes neem - dit was die hoogty van die deur die leerling self saamgestelde bloemlesing as instrument tot literêre waardering - was die gedagtepraat van die mooi plaasdogter Linda teen die einde van die boek 'n geliefkoosde prosakeuse1:

$\mathrm{O}$, haar hart huiwer; sy is bang vir wat kom. Uit die volgroeide somerlewe, die vlammende kleuregeweld om haar, die swaar geur van vrugte in die boord, die deursonde struike en plante en die groot sonne-hemel so wyd-stralend oor alles, kom die boodskap na haar gewonde hart: afskeid. Dit is die ware betekenis van die lewe: dat in alles wat vir jou skoonheid was, waar jou hart aan hang of jy dit nooit

$1 \quad$ In die "Introduction" tot haar bundel essays On histories and stories skryf die romanskrywer en akademikus A.S. Byatt: "I quote extensively and at length. I tell the stories of books, I describe plots. When I first studied English, extensive quotation was a necessary part of the work of the critic ..." (Byatt, 2000:5). Byatt roep dan haar leermeesters op: die beroemde Cambridge-kritici I.A. Richards en F.R. Leavis, wie se invloed ook my "English studies" en ander literatuurstudie in die vyftigerjare van die vorige eeu bepaal het. Daarom het ek die vrymoedigheid om haar na te volg deur uitvoerig uit C.M. van den Heever se werke aan te haal. 
kan verloor nie, die afskeid reeds te lees is (Van den Heever, 1961:143).

Later, toe ek student was op Stellenbosch, sou my ou letterkundeleermeester, professor Fransie Malherbe, ons daarop attent maak hoe Van den Heever verraai dat dit eintlik sy ouktoriële verteller is wat deur Linda praat: "Dit is so vol en magtig in die meisie se hart, gedagtes wat te geweldig vir haar siel is, maar wat in haar opstyg soos die krag van die natuur, van die somer self ..." (Van den Heever, 1961:144).

By latere herlees het ek dié outeursgedrag só leer verstaan: Van den Heever kies juis die mooi, liewe meisie om draer te wees van die sentrale gedagte in sy boek. Al die vernaamste inhoude van Somer word in die teken van verganklikheid, van onontwykbare afskeid aangebied. Alles gaan verby: die somerseisoen self, die seisoensgebonde arbeid op die plaas, die plaas as "boereparadys" wat bedreig word deur veranderende ekonomiese omstandighede, en natuurlik, die liefde tussen Linda en die swerwer Wynand, deur 'n misstap waarvoor hy wel sy straf uitgedien het, maar homself nie kan vergewe nie, gedoem om steeds van vertroudes afskeid te neem en verder te swerf.

My vroeë lees van Laat vrugte het my dié roman laat verstaan as in die eerste plek die stryd tussen vader en seun: oom Sybrand, die nors, inhalige, grondhonger boer, en die driftige Henning. Die jong leser sou ongetwyfeld partydig gewees het vir Henning, en die beroemde openingstoneel van die roman - waar Henning 'n ongeleerde perd moet inbreek, sy pa hom daarin na die kroon wil steek en verneder word besit profetiese gehalte vir die verloop van die boek. Oom Sybrand sal die stryd verloor, maar dit is uiteindelik nie Henning wat "wen" nie, maar die meedoënlose patroon wat oudword en aftakeling in die mens se bestaan skep.

\section{Ruimte - 'n kernmotief in Laat vrugte}

In 1986 het J.L. van Schaik Uitgewers besluit om 'n nuwe sagtebanduitgawe van Laat vrugte voor te berei, met veral eietydse studentelesers in gedagte, en ek is gevra om daarvoor 'n kort voorwoord te skryf. (Dié nuwe uitgawe het in 1987 verskyn.) In hierdie herlees van die groot plaasroman in die Afrikaanse tradisie het dit my opgeval hoedat gebrek aan ruimte een van die kernsake van die roman is (vgl. Botha, 1987). Drie generasies bewoon die familieplaas Boskloof: Ouma Willa; haar seun Sybrand en sy vrou Betta, sy suster Maria en haar man Gert as tweede generasie, en Henning, Sybrand se seun. Sybrand se allesoorheersende begeerte is om die hele Boskloof te besit - daar moet 
ruimte wees vir sy ambisie, sy hartstogtelike werkywer en honger na steeds meer besittings.

Hy kan sy suster se deel met sluwe sakesin bekom, maar Ouma Willa oefen onversetlik haar lewensreg op die grond uit, perk hom in.

'n Ander perspektief op ruimte in die roman is dié van Henning. Geknel deur sy vader se tirannie, soek hy sy vryheid buite die grense van Boskloof, en dié soeke sentreer in sy liefde vir Johanna, dogter van Sybrand se buurman Jaap, vir wie Sybrand met ergernis en naywer betrag.

Dit was vir my of drie vroue, uit die drie generasies, op 'n besondere wyse hierdie kernmotief in Laat vrugte belig: Ouma Willa, Betta, Johanna. Ouma Willa, in die uitoefening van haar regte, stel paal en perk aan Sybrand se grondhonger. Sy eis haar eie ruimte op, sy handhaaf haar gesag, oor haar werf en haar werkers, haar kinders, haar goed. Maar aan háár sal ook 'n perk gestel word: die perk van sterflikheid. Dit is van die begin af sigbaar in die vermeerderende tekens van die liggaamlike aftakeling, en daar is iets byna genadeloos in Van den Heever se uitbeelding van haar:

So sit sy met die wasemende koffie naby haar fyn deurvoorde lippe; die vel lyk soos goed gelooide leer met dun, kruisende lyntjies en barsies daarop en hier en daar 'n donkerige kol ... Sterk staan haar wangbene naas die wilskragtige neus uit, wat maklik aan 'n man kon behoort het. En uit die afgeleefde maar stoere gesig staar twee blou oë, wat met oomblikke lyk of hulle blind is (Van den Heever, 1939: 43).

Wanneer ouma Willa egter haar einde voel naderkom, sal die onbarmhartige blik van die verteller versag: Ouma Willa maak alles in orde; sy beweeg na die groot klerekas in haar kamer:

(L)angsaam skuiwe sy 'n laai oop. 'Og Here! Og Here! Wat is die mens?' Haar hande frommel diep onder die klere in en kom met 'n pakkie te voorskyn wat netjies in dun, wit papier toegedraai is. Sy vou die papier versigtig los, en die naghemp, wat sy aangetrek het toe sy op haar wittebroodsdae was, vou geluidloos en syig daaruit en plooi, met fyn kreukelinge, grond-toe. Sy hou dit teen haar bors asof sy dit wil aanpas. Koud en wit hang dit teen haar af, en vir 'n oomblik is dit of sy wil flou word. Sy is so moeg, so doodgedaan. Dan kyk sy weer om haar. Sy weet nog so goed hoe daardie tye was, toe sy lenig en jonk aan die deur van 'n nuwe lewe staan en klop het, toe die dae vol en onmeetlik was van liefde en hartstog. Sy het die naghemp gebêre, soos dit hoort, om daarin begrawe te word. Sy vou dit weer netjies reg en sit dit op die kas net voor haar bed 
sodat dit vlak by der hand is as hulle dit nodig kry ... (Van den Heever, 1939:126).

Betta, Sybrand se vrou, se bestaan spreek van 'n byna totale gebrek aan ruimte. Sybrand eis alles op,

... in 'n stroewe, saaklike huwelikslewe, waarin sy al meer tot die rol van huisbediende verneder is ... Haar hande het maer en kneukelig geword van die werk, dag-in, dag-uit; haar liggaam het verval tot die skouers rond afhang en die maag lelik uitsteek onder die plat bors. Net in haar sagte grys oë is nog die verre weemoed van dié vroue wat soos baie in haar omgewing rusteloos swoeg ... sonder avontuur of afleiding ... (Van den Heever, 1939:30).

As Henning van Boskloof af deur sy pa weggejaag word, kos dit haar dood. En tog, in die oomblikke voor "'n swart vloed oor haar bewussyn kom", beleef ook sy haar jong liefde, die sonnedag van haar huwelik, met langs haar "haar sterk, hartstogtelike bruidegom": "Dit word wit en stil in haar van 'n groot geluk net soos op daardie dag ..." (Van den Heever, 1939:237). - Wat is die mens, sou die leser ook hier wou vra: dat die geluk van liefde en hartstog enersyds so vervlietend is, so deerlik verniel word deur die harde realiteite van 'n lewe, maar dat die gewaarwording daarvan jou tot in jou sterwensuur bybly?

Johanna is vir Henning die lewensruimte self: die leid-ster van sy drome, begeerte, ideale - alles waarvoor daar onder die dwingelandy van Sybrand op Boskloof nie plek is nie. Hy dink aan 'n ontmoeting met Johanna, en "sy kamer word ruim en vol gefluisterde liefdeswoorde. Dit is of die groot, mooi dinge van die wêreld wat ver was van hom, wat hy as verlore beskou het, opeens naby, ontstellend naby hom is ..." (Van den Heever, 1939:99). Hy is onderweg na sy afspraak met haar en "hy voel hoe die weldadige, dansende lug deur sy liggaam ingedrink word en hoe die wydtes van die vredige dag dan weer van hom wegstroom na die horison of hy daarin opgaan, daarin gedagteloos vervlugtig ..."( Van den Heever, 1939:109).

En só ervaar Johanna - ingeperk deur konvensies en deur haar ouers se fel afwysing van Henning, wat vir hulle slegs die klein robbies van daardie beesgesig-Sybrand is - haar ontwakende liefde vir Henning:

Dit is skielik of die nag met die ster-verheerlikte hemel vertroulik na haar toe kom, of dit, buite kleinlike menslike rusies, haar uitnooi na die groot fees van die lewe, ewig onafwysbaar aanwesig vir hulle wat werklik liefhet. Die sterrenag omsluit haar klein lewentjie soos 'n nietige punt, en tog gaan sy uit na die ruimte wat te lank vir haar geslote was ... ( Van den Heever, 1939:122, 123). 
Henning en Johanna sal opstaan teen die vyandskap, die konvensies wat hul bind en skei, en hul liefde sal uiteindelik oorwin. Hul liefde sal ook die hardheid van die vaders versag. Maar voordat dit gebeur, sal Johanna buite-egtelik Henning se kind verwag, en die uitbeelding van haar vertwyfeling en verlatenheid skep van die deerniswekkendste bladsye in die roman.

\section{Die natuur ook 'n hoofspeler}

Soos in sovele van Van den Heever se romans, is die natuur ook hier 'n hoofspeler. Maar waar die verbygaan van die seisoen in Somer die boodskap van afskeid aan die gewonde hart van Linda en aan die leser moes bring, lees ons uit Laat vrugte, teen al die krasheid en teenstand van die natuur waarmee die boer te doen kry in, uit haar onverbiddelike sikliese voortskryding, 'n boodskap van streng genade af.

Aan die einde van die boek is oom Sybrand sterwend. Maar hierdie laaste reis van hom word voltrek wanneer die aarde uit haar winterslaap aan 't ontwaak is.

Die knoppe glans aan die takke en die amandelboom se eerste wit skemer al agter die dun rafels van die wilkerbome uit. Die blare sal kom, die warm gras langs die blinkende fonteindam sal groen en welig soos mos onder die voete insak en die populiere sal met hulle jong glansende blare 'n himne van die aarde sing as die voorjaarswind hulle streel. Hulle sal die ou lied laat bewe oor die plaas, 'n lied van die groot herontwaking wat steeds weer sal kom nadat die blare geval het ... (Van den Heever, 1939:382).

Henning en Johanna keer betyds terug na Boskloof met hul seuntjie. Oom Sybrand kan dan in berusting sterwe, "en dit is goed, dit is 'n diepe troos om te weet dat hy, wat straks soos 'n herfsblaar grond toe sal moet daal, deur Henning, deur sy kleinkind verbonde is aan die oneindige kringloop van die tye en aan God" (Van den Heever, 1939:385).

\section{Liefde verhef bo die getye}

Dit is die liefde, wat so duursaam is in die lewe van dié drie vroue in Laat vrugte - so lyk dit my moet 'n mens die boodskap van die besondere rol wat die vroue daarin speel, vertolk - wat die sterwe draaglik maak en die voortgang van geslagte in harmonie met die groot, oorkoepelende ritme van die natuur, sal verseker.

Dit moes in hierdie jare gewees het, tussen die verskyning in 1939 van haar bundel Die stil avontuur en Die vrou en ander verse van 1945, dat Elisabeth Eybers geskryf het: 
Somer en herfs en winter trek in wye onafgebroke wisseling deur die land, maar sý bly draer van die lente want liefde het haar verhef bo die getye ...

(Eybers, 1945:7)

\section{Vroue as betekenisdraers}

So kan 'n mens dan vasstel dat Van den Heever van vrouekarakters in sy twee groot klassieke prosawerke besondere betekenisdraers maak. Dit het my nuuskierig gemaak oor sy vroeër, miskien minder hoog geskatte werk. Het hierdie eienskap deur sy werk heen gegroei om in Laat vrugte 'n hoogtepunt te bereik?

Die vraag het my, en dit vir die eerste keer in baie jare, na die twee romans teruggeneem wat aan die begin staan van Van den Heever se oeuvre: sy eerste prosawerk, die novelle Op die plaas (1927) en Langs die grootpad (1928).

Dit het my al dikwels opgeval hoedat verwantskappe tussen die onderskeie werke van 'n outeur die indruk skep dat hulle brokstukke is van een groot werk; of anders, kan beskou word as herhaalde pogings om aan sekere inhoude, temas, patrone, sinvol gestalte te gee. So kom vroeë werke, in die lig van wat 'n skrywer later lewer, byna voor soos vingeroefeninge.

Op die plaas, 'n skraal boekie van 96 bladsye in die heruitgawe van 1982, is vir my bevestiging van hierdie vermoede. Freek, die hoofkarakter, is 'n soort outsider, 'n eenvoudige siel wat eenkant, eensaam woon op sy stukkie grond wat hy innig liefhet. Sy lewe word versteur, maar ook verruim deur die koms van die stadsmeisie Miem, wat by sy bejaarde bure kom kuier. Sy is vir hom aanbiddelik mooi, en vir 'n kort tyd word sy lewe deur sy ontwakende liefde vir haar verhef bo die sleurgang van sy daaglikse, immer herhalende take. Maar Miem behoort tot die stad - en reeds hier aan die begin van Van den Heever se prosaoeuvre staan stad en land vyandig teenoor mekaar - en sy sal daarheen teruggaan en 'n eie lewe saam met 'n ander geliefde voortsit.

Tog, die verhewigde skoonheidservaring wat sy in hom teweegbring ook die vertroude landskap word mooier as tevore - omskep die lewe tot iets groots en wyd.

Dit is net of sy liefdesgeskiedenis hom tot besinning reggeruk het ... Hy voel die eensaamte om hom, maar hy is tevrede, want hy begryp nou iets van die groot lewe ... En Freek vergeet sy eensaamheid en 
voel heeltemaal een met die nag se ligtende wêrelde om hom (Van den Heever, 1982 (1927):95, 96).

Die vrou, as voorwerp van aanbidding, maar terselfdertyd as instrument tot die verkryging van dieper lewenskennis, groter skoonheidsbelewenis - dit word aansienlik sterker uitgewerk in Langs die grootpad.

Sentraal daarin is Hansie, seun van die boer oom Gert, maar sonder aanleg vir die boerdery. Hy speel liewer sy viool, en daarin laat hy dink aan 'n opstel van N.P. van Wyk Louw in Maskers van die erns (1955), "Wat kon daarvan word?": "Wat het van talente geword in 'n lewenskring waar geeneen van dié dinge bestaan het nie: musiek as kuns, wysbegeerte, poësie, wiskunde, skilderkuns?" vra Van Wyk Louw daarin (Louw, 1955:5-8).

As jong seun op sy pa se plaas besef Hansie alreeds dat hy lief is vir Maria, die dogter van oom Rooi-Stefaans, die bywoner, wat later wegtrek na 'n botsing tussen hom en oom Gert. Rooi-Stefaans maak 'n fortuin op die delwerye. Maria is in staat om verder te gaan leer in die stad. Hansie moet ook weg van sy ouerhuis na 'n botsing met sy stiefma en stiefbroer, en kom tereg op die plaas van Rooi-Stefaans. Wanneer hy en Maria nou as volwassenes weer ontmoet, groei die liefde tussen hulle; Maria inspireer en ondersteun hom daadwerklik dat hy in die stad by 'n bekende leermeester sal gaan studeer. Hoewel hy sukses behaal, besluit hy en Maria dat hulle na sy pa se dood weer sal terugkeer na die ou plaas toe. Hansie sal komponeer, hulle sal die mense van die omgewing opbou. Boweal sal hulle weer in harmonie met die geliefde landskap, met die glorie van die natuur kan leef. Maria het die voltooiing van hierdie kringloop moontlik gemaak.

Naas die romantiese idealisme van hierdie verhaal, begin ons ook die ontwikkeling opmerk van 'n durende motief in Van den Heever se prosa: sy sosiale bekommernis. Dit blyk in wat daar oor die verwording van die arm, ontwortelde Boeremense op die delwerye en in die krotbuurte van die stad gesê word. Maar die plek van die vrou in die samelewing is ook ter sake: Maria lewer 'n vurige pleidooi daaroor teenoor haar pa: "Die vrou het net soveel reg om haar lewe onafhanklik te maak soos die man ..." En: "... hulle sal mos ook later stemreg kry. Waarom moet die man dit alleen hê? Wie is hulle so danig?" (231) (Onthou die eerste publikasiedatum hier: 1928.)

Een van Van den Heever se sterkste kortverhale, "Leuens" uit Vuurvlieg en sterre (1934 - opgeneem in Grové, 1976) beeld dan ook 'n paar jaar later Van den Heever se kommer oor en mededoë met die misplaastes in die stad op skrynende wyse uit - en dit is twee vroue wat hierin die 
hoofspelers is. Naomi en Olga, gewese skoolmaats op 'n Vrystaatse dorp, loop mekaar na tien jaar weer raak in Johannesburg, in Eloffstraat. Olga het met welslae 'n tuiste vir haar en haar gesin in die stad geskep sy is getroud met 'n welvarende geneesheer, en woon in 'n deftige huis in Saxonwold. Daar, op Olga se uitnodiging, kom Naomi haar vanuit haar vervalle, beknopte huisie in Vrededorp besoek. Naomi was die dogter van die rykste boer in die Vrystaat, nou bankrot; getroud met 'n swakkeling, vroeër onderwyser, nie in staat om 'n werk te hou nie. Dit word 'n eenmalige besoek. Naomi, die slim kind, vroeër so vol ideale en drome, kan haar slegs met leuens teenoor haar eertydse vriendin handhaaf. Armoede, sosiale agteruitgang, het haar menswaardigheid afgetakel; in deemoedige aanvaarding van haar lot herwin sy ten slotte iets van haar onvernietigbare onafhanklikheidsgees (vgl. Botha, 1990).

Ek het tot dusver net oor die simpatieke vrouekarakters gepraat. Hulle maak meermale deel uit, soos die magtige panorama van die SuidAfrikaanse "natuurglorie", van wat 'n mens "skoonheidstroos" mag noem teenoor die harde en bitter werklikhede wat durend aanwesig is in Van den Heever se boeke.

'n Mens mag egter nie verswyg nie, dat Van den Heever se verhale ook bevolk is met ánder tipes vroue: verleidsters, skellers en skinderbekke (volop! - aan dié verskynsel, die werk van die praatduiwel, het Van den Heever 'n spesiale hekel gehad). En ook is daar Wenda, tragiese hoofkarakter in die roman Kromburg van 1937, ons Madame Bovary van die Vrystaatse velde (Dekker, 1941:1971).

Wenda, die mooi, gevoelige dogter van die boer oom Karel van Blerk, trou nadat haar verloofde verongeluk het, met die goedige, maar oervervelige Flip, bestuurder van die Boerewinkel in die dorpie Kromburg. Al is die dorpsnaam kennelik allegories bedoel (die woonplek van 'n krom en verdraaide geslag), sou 'n mens dit amper op die landkaart kon gaan soek - "vyftig myl van Bloemfontein af" (29). Wenda is "anders", en word daarom gruwelik beskinder; sy soek na iets veel ruimer, hoër as wat die kleinburgerlike dorpie haar kan bied - "Waar is die lewe wat haar soos 'n vlam sou opgeneem het?" is haar versugting - woorde wat herinner aan die styl van die laat 19de-eeuse estete (vgl. Botha, 1983).

Sy het talent vir toneel en soek 'n dwase uitvlug saam met 'n bedenklike reisende toneelgeselskap, ook in die grootstad.

Ontnugterd, wanhopig reis sy in 'n "kille najaarsnag" in die kondukteurswa van 'n goederetrein terug na Kromburg, na Flip, na 'n siekbed en na haar dood. Met haar waanbeelde sleur sy haar goedige man, haar toegeeflike vader, ook ander aanbidders mee soos 'n ware belle dame 
sans merci, 'n ware femme fatale. Soos, inderdaad, Madame Bovary. Maar sy word nie deur haar outeur só uitgebeeld dat sy voor ons veroordeeld staan nie. "Dit is Kromburg wat vir Wenda vermoor het!" roep die arme Flip uit. Maar sy gaan eweseer ten gronde aan haar selfbegogeling, haar onstuimige en onmoontlike drome. By alle tekorte wat ' $n$ mens in die roman sou kon aanmerk, is daarin tog 'n romantiese heldin geskep volgens die voorbeeld van die groot 19de-eeuse tradisie.

'n Versreël van die Nederlandse digter J.C. Bloem kom by 'n mens op (uit sy gedig "Het gestorven meisje"): "De wereld heeft geen plaats voor zulk een lieflijkheid."

Die opsoek van die vroue in Van den Heever se boeke maak die sentimentalis in my wakker. Daarom heg ek groot betekenis daaraan dat ek tussen al die boeke van C.M. van den Heever wat ek besit, net twee kon vind met 'n opdrag. Dit is Langs die grootpad, opgedra: "Aan Martie, my vrou" en sy essaybundel van 1935, Die Afrikaanse gedagte, waarin die opdrag voorin lui: "Ter nagedagtenis aan MY MOEDER die moedige Afrikaanse vrou."

Die naspeur van die aard en rol van die vrouekarakters in C.M. van den Heever se prosawerke, so lyk dit my, bring die leser digby die hart van sy skrywerskap.

\section{Bibliografie}

Botha, Elize. 1983. Verskyningsvorme van die romantiek in die Afrikaanse prosa: D.F. Malherbe en daarna. D.F. Malherbe-gedenklesing no. 2. Bloemfontein : Universiteit van die Oranje-Vrystaat.

Botha, Elize. 1987. Inleiding. In: Van den Heever, C.M. Laat vrugte. Pretoria : Van Schaik.

Botha, Elize. 1990. Die trek na die stad. In: Verstedeliking as kultuurhistoriese verskynsel. Kongresreferate, SA Vereniging vir Kultuurgeskiedenis.

Byatt, A.S. 2000. On histories and stories - Selected essays. London : Chatto \& Windus.

Dekker, G. 1941. Afrikaanse literatuurgeskiedenis. Kaapstad/Bloemfontein/Port Elizabeth : Nasionale Pers.

Eybers, Elisabeth. 1945. Die vrou en ander verse. Johannesburg/Pretoria : Constantia/De Bussy.

Grové, A.P. 1976 [1971]. Hoogtepunte in die Afrikaanse verhaalkuns. Kaapstad : Tafelberg.

Louw, N.P. van Wyk. 1955. Maskers van die erns. Johannesburg : Afrikaanse PersBoekhandel.

Nabokov, Vladimir. 1983. Lectures on literature. London : Pan Books.

Van den Heever, C.M. 1930 [1928]. Langs die grootpad. Pretoria : Van Schaik.

Van den Heever, C.M. 1937. Kromburg. Kaapstad/Bloemfontein/Port Elizabeth : Nasionale Pers.

Van den Heever, C.M. 1987 [1939]. Laat vrugte. Kaapstad/Bloemfontein/Port Elizabeth : Nasionale Pers. 
Van den Heever, C.M. 1961 [1935]. Somer. Pretoria : Van Schaik.

Van den Heever, C.M. 1976. Leuens. In: Grové, A.P. Hoogtepunte in die Afrikaanse verhaalkuns. Kaapstad : Tafelberg. p. 87-94.

Van den Heever, C.M. 1982 [1927]. Op die plaas. Kaapstad/Johannesburg/Pretoria : Human \& Rousseau.

\section{Kernbegrippe:}

C.M. van den Heever: vrouekarakters

sentrale temas: oeuvre van C.M van den Heever

\section{Key concepts:}

C.M. van den Heever: women characters

central themes: oeuvre of C.M. van den Heever 
